pronounced in foetuses : its weight was increased by 2.2 in the Jet Neuf group $(P<0.001)$ and by 1.4 (NS) in the Tandem group. This criterion was not affected by the lactation diet, whereas the effects of the pregnancy diet persisted in piglets at weaning. It was concluded that foetal thyroids are particularly sensitive to goitrogenic compounds of normal rapeseed meal.

Feeding pregnant gilts with normal or low glucosinolate rapeseed meal increased early embryonic mortality $(\mathrm{P}<0.001 ; 47.3,40.1$ and $29.1 \%$ in the Jet Neuf, Tandem and control groups, respectively). Likewise, total embryonic mortality was higher $(19.4,44.1$ and $31.4 \%$, respectively), but mortality after 40 days of gestation was not affected. Prolificacy of gilts fed rapeseed meal was therefore lower $(P<0.01 ; 10.7,8.5$ and 9.1 total piglets born in the control, Jet Neuf and Tandem groups, respectively). Increased embryonic mortality mainly concerned some gilts and did not seem to be related to the goitrogenic properties of rapeseed meal. Postnatal piglet mortality tended to be higher in litters from dams fed normal rapeseed meal during pregnancy $(30.2 \%$ in the Jet Neuf vs, $18.3 \%$ in the Tandem and $19.8 \%$ in the control groups).

In our experimental conditions, feeding diets containing $20 \%$ rapeseed meal to lactating gilts had no effect on reproductive performance. Using low glucosinolate rapeseed meal minimized the goitrogenic effects of normal rapeseed meal. Reasons for increased embryonic mortality due to rapeseed meal intake should be investigated.

\title{
Comparison of three levels of dietary lysine in the bacon pig Influence of the genotype
}

\author{
F. GATEL, F. GROSJEAN
}

\author{
I.T.C.F., 8, avenue du Président-Wilson, 75116 Paris
}

A trial was made in 48 Large White and 48 Pen ar Lan females kept and fed individually between 30 and $100 \mathrm{~kg}$ live-weight to compare three dietary treatments exhibiting a different lysine content $(2.6,2.8$ and $3.2 \mathrm{~g} / 1000 \mathrm{kcal} \mathrm{DE})$. The diets consisted of $58.3 \%$ wheat, $20.0 \%$ barley, $18.2 \%$ soyabean meal and $0,0.12$ or $0.24 \%$ lysine $\mathrm{HCL}$ and were offered according to the same feeding pattern.

Whatever the period, feed intake was similar with the three treatments and in the two breeds. Between 40 and $60 \mathrm{~kg}$ live-weight, feed conversion ratio was improved when the level of dietary lysine was higher $(2.67,2.62,2.57$ in Large White and $2.75,2.60,2.61$ in Pen ar Lan females). During the finishing period $(60-101 \mathrm{~kg})$, feed conversion ratios were not significantly different $(3.16,3.19,3.20,3.12,3.08,3.14)$. When considering the whole fattening period $(40-101 \mathrm{~kg})$, the differences observed in feed conversion ratios were no more significant $(3.00,3.00,2.99$ in Large White and 3.00, 2.93 and 2.94 in Pen ar Lan females). Carcass yield was neither affected by the diet nor by the breed. Muscle percentage was influenced by the breed but not by the level of lysine $(50.0,51.5,51.8 ; 54.0,53.9$ and $54.4 \%)$. Likewise, the technological quality of hams was dependent of the genotype but was not affected by the diet. It was concluded that the level of $2.6 \mathrm{~g}$ of lysine $/ 1000 \mathrm{kcal} \mathrm{DE}$ is recommended in growing-finishing pigs whatever the breed.

\section{Influence of sex and castration on the response of growing pigs to dietary lysine concentration}

\author{
J. LOUGNON, T. KIENER
}

\author{
A.E.C., Service Développement Alimentation Animale, 03600 Commentry
}

The responses of entire male, castrated male and female growing pigs to dietary lysine concentration was investigated in an experiment involving 144 animals. 